\title{
THE RÔLE OF CUMULUS CELLS AND THE ZONA PELLUCIDA IN FERTILIZATION OF MOUSE EGGS IN VITRO
}

\author{
A. PAVLOK AND ANNE MaLAREN \\ Czechoslovak Academy of Sciences, Laboratory of Animal Genetics, \\ Liběchov, Czechoslovakia, and Agricultural Research Council Unit of Animal Genetics, \\ Institute of Animal Genetics, Edinburgh \\ (Received 23rd Fuly 1971, accepted 27th September 1971)
}

Summary. Mouse eggs were fertilized in vitro, in the presence and absence of cumulus cells and the zona pellucida, confirming that cumulus cells are not necessary for the fertilization of mouse eggs with capacitated spermatozoa. The findings suggest that cumulus cells produce a substance capable of inducing capacitation.

After lysis of the zona pellucida, the fertilization rate with capacitated (uterine) spermatozoa was higher than, and with non-capacitated (epididymal) spermatozoa was at least as high as, the fertilization rate of control eggs with an intact zona. Washing and resuspension in a chemically defined medium almost entirely prevented fertilization with epididymal spermatozoa when the zona was present, but had no effect after its removal. Capacitation of mouse spermatozoa appears to be required for the penetration of the zona pellucida only, not for entry into the vitellus.

When the eggs and spermatozoa were incubated in the same chymotrypsin solution which had induced lysis of the zona, the percentage of eggs penetrated by more than one spermatozoon was increased.

\section{INTRODUGTION}

Successful fertilization of mouse eggs in vitro has been achieved by the use of capacitated uterine spermatozoa, or by spermatozoa from the cauda epididymidis or from the ductus deferens in the presence of oviducal fluid (Whittingham, 1968; Mukherjee \& Cohen, 1970), or by epididymal spermatozoa capacitated in cows' follicular fluid (Iwamatsu \& Chang, 1969, 1970). Since Iwamatsu and Chang's experiments proved that the presence of cumulus cells was not required if the spermatozoa were capacitated in bovine follicular fluid, we were concerned to investigate the positive effect of cumulus (i.e. follicle) cells on the capacitation of epididymal spermatozoa.

The absence of any need for an intact zona pellucida in the process of fertilization in vitro has only been demonstrated in rat eggs (Toyoda \& Chang, 
1968). The results suggested that the vitelline membrane of rat eggs lacking a zona pellucida might be penetrated even by uncapacitated (epididymal) spermatozoa. The aim of the present experiments was to confirm in mice the findings of Toyoda \& Chang (1968), and at the same time to eliminate the possible capacitating effect of the oviducal fluid, the lysed zona pellucida and the suspended cumulus cells so that fertilization would proceed in a chemically defined medium.

\section{MATERIAL AND METHODS}

Preliminary experiments were carried out on mice of the randomly bred $Q$ strain. For the main experiments, the females were F5 animals from the cross (o $\mathrm{C} 57 \mathrm{BL} 10 \mathrm{ScSn} / \mathrm{Ph} \times$ of $\mathrm{A} / \mathrm{Ph}$ ) and the males were from the back-cross (क C57BL10ScSn/Ph $\times$ o (क $\mathrm{G} 57 \mathrm{BL} 10 \mathrm{ScSn} / \mathrm{Ph} \times \approx \mathrm{A} / \mathrm{Ph}) \mathrm{F}_{5}$ ). The animals were 2 to 3 months of age. Superovulation was induced by a subcutaneous injection of 4 to 5 i.u. PMSG (Bioveta), followed 36 to $40 \mathrm{hr}$ later by 25 i.u. HGG (Praedyn; Spofa). The females were killed 13 to $14 \mathrm{hr}$ after the second injection. After removal, the oviducts were rinsed with culture medium and transferred to a watch glass containing paraffin oil. The eggs in cumulus oophorus were dissected out from the oviduct and released with the oviduct fluid into the paraffin oil. One group of eggs from four to six oviducts in $30 \mu \mathrm{l}$ medium served as control. Another group of eggs was washed three times in culture medium and was also placed in $30 \mu \mathrm{l}$ medium under paraffin oil. The third group of eggs was similarly washed and isolated into paraffin oil and then transferred into $0.2 \mathrm{ml}$ culture medium with 0.025 to $0.03 \mathrm{mg} / \mathrm{ml}$ hyaluronidase (USOL; activity 190 turbidimetric units $/ \mathrm{mg}$ ). After 10 to $15 \mathrm{~min}$, the cumulusfree eggs were again washed three times in culture medium. Half were placed in a 30- $\mu$ l drop of culture medium under paraffin oil and the other half were transferred to an equal amount of culture medium containing oviduct fluid. This fluid had been obtained from the same oviducts that had yielded the hyaluronidase-treated eggs.

Another group of eggs was isolated from the oviducts under paraffin oil into $10 \mu \mathrm{l}$ medium with $0.3 \mathrm{mg}$ crystalline $\alpha$-chymotrypsin (29.5 benzoyl-tyrosinethylester units $/ \mathrm{mg} / / \mathrm{ml}$ and incubated for 25 to $30 \mathrm{~min}$ at a temperature of $37.5^{\circ} \mathrm{C}$. After dissolution of the zona pellucida, half the eggs were left in the original suspension containing oviduct fluid, chymotrypsin, culture medium, cumulus cells and lysed zonae pellucidae, while the other half were washed three times in culture medium and again placed in $30 \mu \mathrm{l}$ culture medium under paraffin oil.

The composition of the basic culture medium ( $\mathrm{pH} 7 \cdot 6$ ) was: isotonic solution of TGM 199 (USOL), $72 \mathrm{ml} ; 1.32 \% \mathrm{NaHCO}_{3}+0.002 \%$ phenol red, $18 \mathrm{ml}$; $6.2 \%$ glucose solution, $10 \mathrm{ml}$; Na-pyruvate, $0.004 \mathrm{~g}$; lyophilized bovine serum albumin (Imuna), $0.3 \mathrm{~g}$; penicillin, $50 \mathrm{i.u.} / \mathrm{ml}$; and streptomycin, $50 \mathrm{i} . \mathrm{u} . / \mathrm{ml}$.

Uterine spermatozoa were obtained from mice mated $1 \frac{1}{2}$ to $2 \frac{1}{2} \mathrm{hr}$ previously. Epididymal spermatozoa were obtained from freshly killed males by flushing both the ductus deferens and the distal parts of the epididymis with culture medium $\frac{1}{2} \mathrm{hr}$ or $2 \frac{1}{2} \mathrm{hr}$ before spermatozoa and eggs were mixed. To obtain spermatozoa of high activity, it was necessary to prevent forcible dispersion of 
sperm clusters. They had to be left in a small amount of medium for about 20 min to disperse spontaneously to a concentration of 20 to $50 \times 10^{6} / \mathrm{ml}$. The final concentration of spermatozoa in the medium with eggs ranged from 2 to $6 \times 10^{6} / \mathrm{ml}$.

After adding the spermatozoa, the eggs in Petri dishes were incubated at $37.5^{\circ} \mathrm{C}$ in an environment of $95 \%$ oxygen and $5 \% \mathrm{CO}_{2}$. The humidity was kept at about $90 \%$.

The eggs were isolated 5 to $6 \mathrm{hr}$ after the beginning of incubation, mounted between a microscope slide and cover glass and investigated first by phase contrast microscopy and later in more detail after fixation with acetic alcohol and acetic orcein staining. In order to prevent rupture of the vitelline membrane, eggs without a zona pellucida had to be placed for several minutes into culture medium containing bovine serum albumin before transferring them to a microscope slide. Eggs were regarded as fertilized when they displayed at least

TABLE 1

THE PERGENTAGE OF MOUSE EGGS FERTILIZED in vitro WITH EPIDIDYMAL SPERMATOZOA IN THE PRESENGE OR ABSENCE OF OVIDUCT FLUID AND GUMULUS CELLS

\begin{tabular}{|c|c|c|c|c|}
\hline Experiment* & $\begin{array}{l}\text { Control group } \\
\text { (cumnlus and oviduct } \\
\text { fluid present) }\end{array}$ & $\begin{array}{l}\text { Cumulus present, } \\
\text { eggs washed three times }\end{array}$ & $\begin{array}{l}\text { Cumulus removed, } \\
\text { eggs washed three times }\end{array}$ & $\begin{array}{l}\text { Cumulus removed, } \\
\text { eggs washed three times, } \\
\text { transferred to } \\
\text { medium with oviduct } \\
\text { fluid }\end{array}$ \\
\hline $\begin{array}{l}1 \\
2 \\
3 \\
4 \\
5\end{array}$ & $\begin{array}{l}63.3(30) \dagger \\
21.4(56) \\
70.0(50) \\
68 \cdot 2(22) \\
55.0(40)\end{array}$ & $\begin{array}{l}22 \cdot 2(27) \\
13 \cdot 3(45) \\
30 \cdot 6(36) \\
50 \cdot 0(12) \\
42 \cdot 1(38)\end{array}$ & $\begin{array}{r}13 \cdot 3(30) \\
0 \cdot 0(64) \\
8 \cdot 0(50) \\
5 \cdot 0(20) \\
12 \cdot 5(32)\end{array}$ & $\begin{array}{l}53 \cdot 8(26) \\
39 \cdot 2(51) \\
61 \cdot 1(54) \\
55 \cdot 5(18) \\
53 \cdot 1(32)\end{array}$ \\
\hline Total & $52 \cdot 0(198)$ & $28 \cdot 4(158)$ & $6 \cdot 6(196)$ & $51.9(181)$ \\
\hline
\end{tabular}

* Spermatozoa were preincubated in culture medium for $2 \frac{1}{2} \mathrm{hr}$ in Exps 1 and 2, and for $30 \mathrm{~min}$ in Exps 3,4 and 5 .

$\dagger$ Percentage of eggs fertilized, followed in parentheses by the number of eggs examined.

one swollen spermatozoon (including the tail) in the cytoplasm and were at anaphase or telophase of the second meiotic division (Pl. 1, Fig. 3), or when they contained at least one male and one female pronucleus (Pl. 1, Figs. 4 and 5) and a second polar body. In the case of pronuclei, it was generally possible to identify the tail of the transformed spermatozoon (Pl. 1, Fig. 6).

The control groups showed statistically significant heterogeneity in fertilization rate between experiments $(P<0.001$ for heterogeneity between control groups for the data in Table 1 and for that in the upper part of Table 2). The data for each experiment are therefore tabulated separately. Statistical comparisons between groups have been made in the first instance within experiments, and subsequently combined using the 'log odds' method.

\section{RESULTS}

The rôle of cumulus cells and oviduct fluid during fertilization in vitro

Table 1 shows the fertilization rate according to the treatment of the eggs,

G 
and Pl. 1, Figs. 1 to 4 show the appearance of eggs fertilized in vitro. The fertilization rate was almost identical in the control group, where cumulus cells and oviduct fluid were both present $(52.0 \%)$, and in the treatment group lacking cumulus cells but maintained in an environment of oviduct fluid $(51.9 \%)$. In the group of eggs maintained with cumulus cells but without oviduct fluid, the fertilization rate $(28.4 \%)$ was significantly lower $(P<0.001$

\section{TABLE 2}

THE PERGENTAGE OF MOUSE EGGS FERTILIZED in vitro AFTER REMOVAL OF THE ZONA PELLUGIDA

\begin{tabular}{c|c|c|c|c}
\hline $\begin{array}{c}\text { Source of } \\
\text { sperm. }\end{array}$ & Experiment & $\begin{array}{c}\text { Control } \\
\text { group }\end{array}$ & $\begin{array}{c}\text { Eggs treated with } \\
\text { chymotrypsin, } \\
\text { not washed }\end{array}$ & $\begin{array}{c}\text { Eggs treated with } \\
\text { chymotrypsin, } \\
\text { washed three times }\end{array}$ \\
\hline Uterine & 1 & $24 \cdot 1(29)^{*}$ & $56 \cdot 1(41)$ & $44 \cdot 8(29)$ \\
& 2 & $56 \cdot 5(23)$ & $65 \cdot 0(20)$ & $53 \cdot 3(15)$ \\
& 3 & $37 \cdot 8(37)$ & $57 \cdot 7(45)$ & $62 \cdot 2(37)$ \\
& 5 & $85 \cdot 0(20)$ & $77 \cdot 7(27)$ & $66 \cdot 7(12)$ \\
& 5 & $25 \cdot 0(24)$ & $70 \cdot 8(24)$ & $78 \cdot 1(32)$ \\
& Total & $42 \cdot 8(133)$ & $63 \cdot 7(157)$ & $61 \cdot 6(125)$ \\
\hline Epididymal & 6 & $49 \cdot 4(95)$ & $50 \cdot 0(64)$ & $66 \cdot 6(24)$ \\
& 7 & $68 \cdot 1(47)$ & $60 \cdot 0(50)$ & $47 \cdot 3(19)$ \\
& 8 & $48 \cdot 4(33)$ & $72 \cdot 2(18)$ & $77.7(27)$ \\
& 9 & $53.5(28)$ & $63 \cdot 3(30)$ & $64 \cdot 7(34)$ \\
& Total & $54 \cdot 1(203)$ & $58 \cdot 0(162)$ & $65 \cdot 4(104)$ \\
\hline
\end{tabular}

* Percentage of eggs fertilized, followed in parentheses by the number of eggs examined.

by comparison with each of the previous two treatment groups). In the fourth treatment group, with few exceptions $(6.6 \%)$, eggs maintained without either cumulus or oviduct fluid remained unfertilized although the surface of each egg was surrounded by hundreds of motile spermatozoa (Pl. 1, Fig. 1).

In Exps 1 and 2, the spermatozoa were incubated at $37.5^{\circ} \mathrm{C}$ for $2 \frac{1}{2} \mathrm{hr}$ before they were added to the eggs, while in Exps 3, 4 and 5, the spermatozoa were added $30 \mathrm{~min}$ after isolation from the cauda epididymidis. There was no in-

\section{EXPLANATION OF PLATE 1}

FIG. 1. Unfertilized eggs incubated in a suspension of epididymal spermatozoa in a chemically defined medium without follicular cells. Hundreds of spermatozoa visible on the surface. Before fixation, phase contrast, approx. $\times 270$.

Frg. 2. Excessive penetration of spermatozoa through the zona pellucida during fertilization in vitro. The zona pellucida displays visible traces of penetration by spermatozoa. Before fixation, phase contrast, approx. $\times 550$.

Fig. 3. Egg fertilized in vitro at early telophase of second meiotic division with swollen spermatozoon (arrowed). Fixation in acetic alcohol, staining with acetic orcein, phase contrast, approx. $\times 420$.

Fig. 4. Egg with two pronuclei (arrowed), fertilized in vitro in oviducal fluid, but without cumulus cells. Before fixation, phase contrast, approx. $\times 550$.

FIG. 5. Egg with two pronuclei (arrowed), fertilized in vitro without the zona pellucida. Before fixation, phase contrast, approx. $\times 700$.

Fig. 6. Egg with visible male pronucleus (long arrow) and tail (short arrow) in the cytoplasm (second pronucleus out of focus) fertilized after lysis of zona pellucida with chymotrypsin. Fixation with acetic alcohol, staining with acetic orcein. Phase contrast. approx. $\times 360$. 
PLATE 1
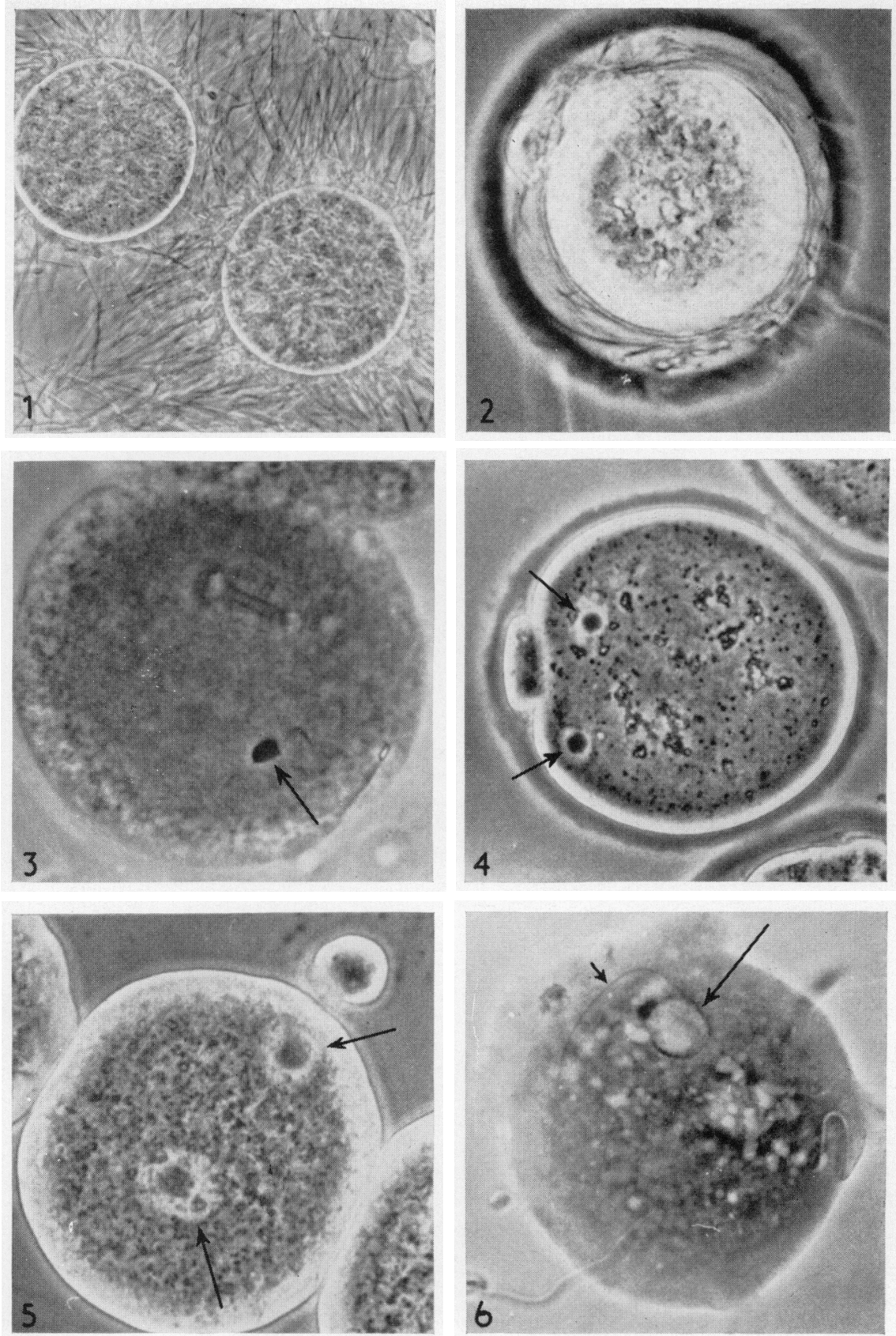
dication of a preference for preincubated spermatozoa in any of the four treatment groups.

Of the 255 eggs fertilized in this experiment, only five were polyspermic, i.e. contained more than one spermatozoon within the vitellus.

\section{Fertilization of eggs in vitro after dissolution of the zona pellucida}

The results given in Table 2 show that dissolution of the zona pellucida by chymotrypsin did not decrease the fertilization rate when compared with that of the control. Indeed, when uterine spermatozoa were used, the zona-free eggs were fertilized at a significantly higher rate than the controls, whether unwashed $(P<0.001)$ or washed three times and fertilized in a chemically defined medium $(P<0.01)$. When epididymal spermatozoa were used, the control

TABLE 3

THE DISTRIBUTION OF POLYSPERMIC MOUSE EGGS FERTILIZED in vitro

\begin{tabular}{c|c|c|c|c}
\hline $\begin{array}{c}\text { Source of } \\
\text { sperm. }\end{array}$ & Experiment & $\begin{array}{c}\text { Control } \\
\text { group }\end{array}$ & $\begin{array}{c}\text { Eggs treated with } \\
\text { chymotrypsin, } \\
\text { not washed }\end{array}$ & $\begin{array}{c}\text { Eggs treated with } \\
\text { chymotrypsin, } \\
\text { washed three times }\end{array}$ \\
\hline Uterine & 1 & $0(7)^{*}$ & $2(23)$ & $2(13)$ \\
& 2 & $0(13)$ & $1(13)$ & $0(8)$ \\
& 3 & $1(14)$ & $5(26)$ & $0(23)$ \\
& 4 & $0(17)$ & $2(21)$ & $0(8)$ \\
& 5 & $0(6)$ & $1(17)$ & $0(25)$ \\
Epididymal & Total & $1(57)$ & $11(100)$ & $2(77)$ \\
& 6 & $0(47)$ & $3(32)$ & $0(16)$ \\
& 7 & $3(32)$ & $7(30)$ & $1(9)$ \\
& 8 & $0(16)$ & $2(13)$ & $0(21)$ \\
& 9 & $0(15)$ & $1(19)$ & $3(22)$ \\
& Total & $3(110)$ & $13(94)$ & $4(68)$ \\
\hline
\end{tabular}

* Number of polyspermic eggs, followed in parentheses by the total number of eggs fertilized.

group showed a higher fertilization rate than with uterine spermatozoa, and the enhancing effect of zona removal upon fertilization was not statistically significant for either of the experimental groups. If the two zona-free groups (washed and unwashed) are combined, the effect of zona removal upon fertilization rate is significantly greater for uterine spermatozoa than for epididymal spermatozoa $(P<0 \cdot 05)$. Plate 1 , Figs. 5 and 6 show zona-free eggs fertilized in vitro.

The data show a marked contrast between the high fertilization rate $(65.4 \%)$ with epididymal spermatozoa for washed zona-free eggs (Table 2) and the very low rate $(6 \cdot 6 \%)$ for similarly washed eggs with the zona intact (Table 1 ).

The numbers of eggs fertilized by more than one spermatozoon are shown in Table 3. Combining the results for uterine and epididymal spermatozoa, the unwashed zona-free eggs showed significantly more polyspermy than either the control group $(P<0.001)$ or the washed zona-free eggs $(P<0.01)$. 


\section{DISGUSSION}

Our results, showing that cumulus cells are not necessary for fertilization with capacitated spermatozoa, are in full agreement with those of Iwamatsu \& Chang (1970). These authors, however, used follicular fluid for the capacitation of spermatozoa whereas, in our experiments, successful capacitation was achieved with oviduct fluid. Bavister (1969) arrived at a different conclusion for hamsters. He regarded oviduct fluid as a suitable environment for the fertilization process but did not think it capable of capacitation. Suggestive evidence for a positive effect of cumulus cells in fertilization comes from the recent work of Cross \& Brinster (1970). They reported that the number of mouse eggs undergoing cleavage after fertilization in vitro with uterine spermatozoa was drastically reduced if the cumulus cells were removed and the eggs washed three times before the spermatozoa were added.

Bavister (1969) concluded that hamster spermatozoa may also be spontaneously capacitated. Yanagimachi (1970) considered that the spontaneous capacitation achieved by Bavister (1969) was stimulated by bovine serum albumin $(2.5 \mathrm{mg} / \mathrm{ml})$ and sodium pyruvate $\left(10^{-4} \mathrm{M}\right)$. Although the medium used in our experiments contained both bovine serum albumin $(3.0 \mathrm{mg} / \mathrm{ml})$ and sodium pyruvate $(0.04 \mathrm{mg} / \mathrm{ml})$, there was no indication of spontaneous capacitation after $2 \frac{1}{2} \mathrm{hr}$ incubation of epididymal spermatozoa (Exps 1 and 2 in Table 1). Gwatkin \& Hutchison (1971) have recently shown that hamster spermatozoa can be capacitated in vitro by $\beta$-glucuronidase, but that some other (so far unknown) substance must be responsible for capacitation in vivo.

The technique of fertilization of rat eggs in vitro after lysis of the zona pellucida with chymotrypsin (Toyoda \& Chang, 1968) is successful in mice also. The high fertilization rate of eggs without the zona pellucida which had been washed three times before incubation with epididymal spermatozoa provides conclusive evidence that the capacitation of mouse spermatozoa is relevant only to the penetration of the zona pellucida and not to the penetration of the vitelline membrane.

The higher frequency of polyspermy in zona-free eggs left in the original chymotrypsin-containing medium cannot yet be satisfactorily explained. It is possible that prolonged contact of the eggs with chymotrypsin may partially damage the mechanism which normally blocks polyspermy.

\section{ACKNOWLEDGMENTS}

The authors wish to express their thanks to Mrs J. Novotná, Mrs M. Langerová and $\mathrm{MrV}$. Pech for technical assistance, and to the Ford Foundation for financial support.

\section{REFERENCES}

Bavister, B. D. (1969) Environmental factors important for in vitro fertilization in the hamster. $\mathcal{F}$. Reprod. Fert. 18, 514.

Gross, P. C. \& Brinster, R. L. (1970) In vivo development of mouse oocytes. Biol. Reprod. 3, 298.

Gwatkin, R. B. L. \& Hutchison, C. F. (1971) Capacitation of hamster spermatozoa by $\beta$-glucuronidase. Nature, Lond. 229, 343. 
Ifamatsu, T. \& Chang, M. C. (1969) In vitro fertilization of mouse eggs in the presence of bovine follicular fluid. Nature, Lond. 224, 919.

Iwamatsu, T. \& Ghang, M. C. (1970) Further investigation of capacitation of sperm and fertilization of mouse eggs in vitro. F. exp. Zool. 175, 271.

Muknerjez, A. B. \& Comen, M. M. (1970) Development of normal mice by in vitro fertilization. Nature, Lond. 228, 472.

Toyoda, Y. \& Chang, M. C. (1968) Sperm penetration of rat eggs in vitro after dissolution of zona pellucida by chymotrypsin. Nature, Lond. 220, 589.

Whittingham, D. G. (1968) Fertilization of mouse eggs in vitro. Nature, Lond. 220, 592.

YANAGIMACHI, R. (1970) In vitro capacitation of golden hamster spermatozoa by homologous and heterologous blood sera. Biol. Reprod. 3, 147. 